\title{
State-of-the-Art Review on Sustainable Design and Construction of Quieter Pavements-Part 2: Factors Affecting Tire-Pavement Noise and Prediction Models
}

\author{
Okan Sirin \\ Department of Civil and Architectural Engineering, Qatar University, P.O. Box 2713, Doha, Qatar; \\ okansirin@qu.edu.qa; Tel.: +974-4403-4179 \\ Academic Editor: Víctor Yepes \\ Received: 16 June 2016; Accepted: 9 July 2016; Published: 20 July 2016
}

\begin{abstract}
Traffic noise is a combination of noises produced from a number of sources. Of all the traffic noise sources, tire-pavement noise, which is emitted as a result of the interaction of rolling, slipping, or dragging tires and the pavement surface, is the dominant contributor of overall noise, particularly when vehicles are moving at higher speeds. Therefore, a number of research studies have been conducted to identify and analyze the factors affecting the generation of tire-pavement interaction noise. This helps in identifying and selecting appropriate noise mitigation techniques. In this paper, an extensive literature survey on the factors affecting tire-pavement noise is presented, and different views on the impact of each individual factor are discussed. From the literature survey, it is also evident that there is a potential correlation between pavement's material characteristics and tire-pavement noise. A comprehensive discussion about this correlation is presented in the paper. In addition, this paper discusses various mathematical models for predicting pavement noise, and their advantages and shortcomings.
\end{abstract}

Keywords: sustainable design; tire-pavement noise; noise measurement; surface texture; sound absorption measurement; noise prediction model

\section{Introduction}

In today's world, a large portion of people and commercial goods are being transported over the highway networks, especially for inter-country transportation. This is because the transportation network improved markedly in recent time. Furthermore, it is also less expensive compared to the other modes of transportation. As a result of these transportation activities, the number of vehicles increases hence noise from highway traffic also increases. Therefore, it possesses a serious environmental problem not only to the road users (i.e., drivers and passengers) but also to the people and animals living near the highways. In addition to annoyance, it possesses a serious threat to human health [1]. Noise coming from the highway traffic can be classified into three general categories: (1) the power unit noise (engine, fan, exhaust, transmission, etc.); (2) the aerodynamic noise, which is related to the turbulent airflow around the vehicle; and (3) the tire-pavement noise. The power unit noise dominates the roadside noise levels at low speeds. As speed increases, a crossover speed (the practical threshold above which quieter pavements will be most helpful) is reached, and beyond this point, the tire-pavement interaction noise becomes the dominant source [2-4]. Only at high speeds, aerodynamic sources will begin to dominate. Figure 1 adopted from the Little Book of Quieter Pavements [2] shows the effect of speed on vehicle noise sources and the crossover speed. 


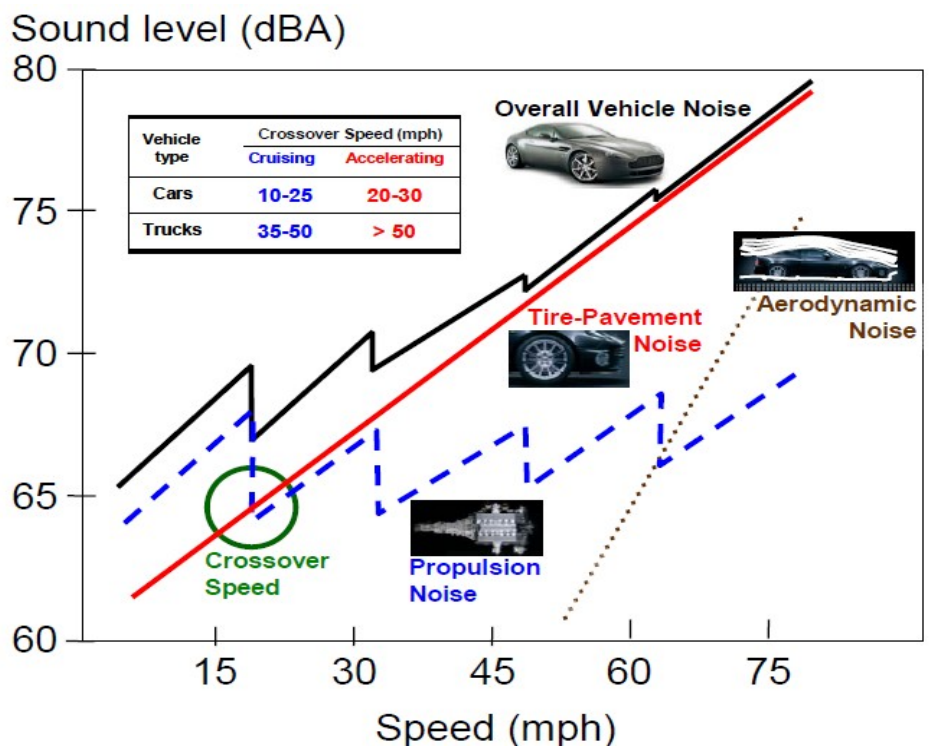

Figure 1. Effect of speed on noise generation [2].

Further study by Donavan and Rymer [5] quantified the contribution of noise generation from specific sources, as shown in Figure 2. They presented that about $78 \%$ of the noise generated is due to tire-pavement interaction, whereas $12 \%$ and $10 \%$ of the noise is contributed from the power train and aerodynamic system, respectively, at speeds of 100 to $110 \mathrm{~km} / \mathrm{h}(62$ to $68 \mathrm{~m} / \mathrm{h}$ ). However, it is important to note that due to advances made in the car industry, manufacturers have developed quieter exhaust and engines as well as a more efficient aerodynamic system to reduce the vehicle noise. Similarly, tire manufacturers are also producing tires that generate lower tire-pavement interaction noise. Therefore, the so-called crossover speed is decreasing. Hence, the study of tire-pavement noise is becoming imperative.

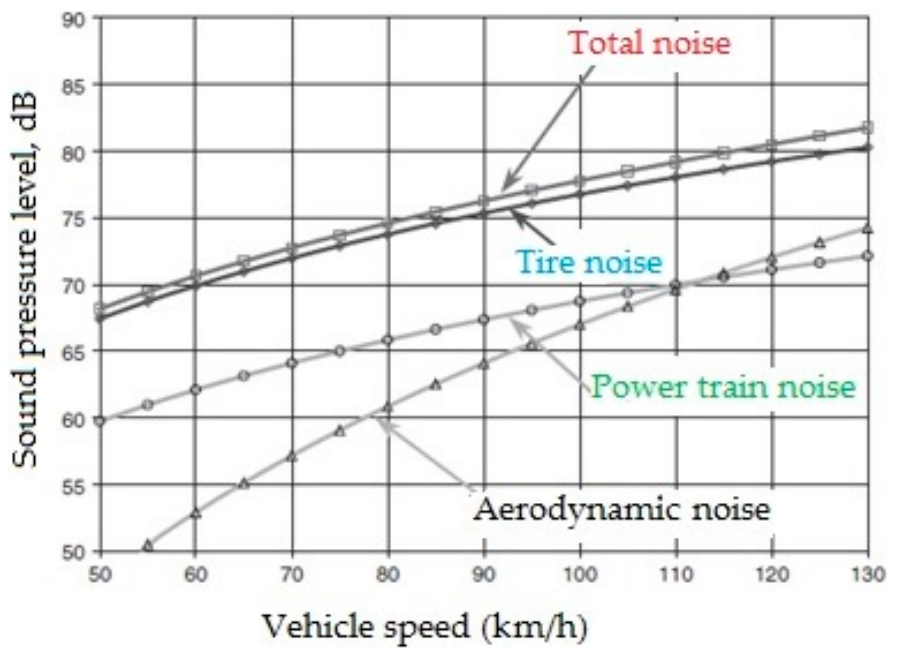

Figure 2. Noise contribution from the different source at the function of speed [5].

Over the years, many researchers have studied the factors affecting the tire-pavement interaction noise by using laboratory and field testing techniques. An extensive literature survey was carried out to collect findings from previous research. This paper summarizes the current state of knowledge on the factors affecting tire-pavement noise and different noise modeling approaches for predicting traffic noise. 


\section{Factors Affecting Tire-Pavement Noise}

Generation and propagation of tire-pavement interaction noise is affected by a number of factors. Therefore, it is important to understand how the various factors influence the noise generation and how it can be controlled, especially tire-pavement noise. This section reviews the most important factors affecting tire-pavement noise.

\subsection{Type of Vehicle}

Generally, various types of vehicles can be observed in a normal traffic stream. Thus, type of vehicle plays a significant role in deciding the level of noise generation. It is reported that if normal traffic contains $10 \%$ or more heavy trucks, the level of traffic noise is dominated by the noise from the trucks [2]. A small passenger car generally produces much less noise compared to heavy vehicles. This is because heavy vehicles normally have a larger tire size in addition to their higher number of tires that causes more tire-pavement interaction noise in comparison to small cars. Furthermore, a heavy vehicle tire generally has a more aggressive tread pattern (with clearly defined blocks and gaps), which produces louder noises [2,4]. Additionally, heavy vehicles with their larger engine/power system contribute in higher noise generation. It was reported that a heavy truck produces $10 \mathrm{dBA}$ higher noise compared to a typical passenger car when travelling above the crossover speed [2].

\subsection{Vehicle Speed}

A good portion of research dealing with highway traffic noise focuses on the effect of vehicle speed on noise generation. A number of research studies [6-13] reported noise level increases with increasing vehicle speed. Of them, Bennert et al. [6] performed noise testing at speeds of 55, 60 and $65 \mathrm{mph}$ on 39 pavement sections in the state of New Jersey. Noise measurements were done with the close proximity (CPX) method by using the National Center for Asphalt Technology (NCAT) noise trailer. It was concluded that tire-pavement noise increases by an average of $0.18 \mathrm{dBA}$ per mile increase of vehicle speed for both hot mix asphalt (HMA) and Portland cement concrete (PCC) surfaces. Their findings were similar to an earlier study conducted by Michigan Department of Transportation [14]. In this study, noise tests were conducted at speeds of 45, 60 and $75 \mathrm{mph}$ on both HMA and PCC surfaces and reported an average $0.2 \mathrm{dBA}$ increase of noise per mile increase of speed. Cho and Mun [7] performed extensive testing on different surfaces at speeds of 50, 60, 70, 80, 90, 100, 110 and $120 \mathrm{~km} / \mathrm{h}$ to isolate the influence of vehicle speed on noise generation. Many types of vehicles (one passenger car, two buses manufactured by different company, one truck, one SUV, one light truck, two medium trucks manufactured by same company but different model, one heavy truck and two trailers manufactured by different company) were used in the testing program and both CPX and Statistical Pass-by (SPB) methods were used for noise measurement. Test data demonstrated that tire-pavement noise increases with increasing speed of vehicle irrespective of vehicle type or surface type.

Donavan and Lodico [8] used the on-board sound intensity (OBSI) method to identify the influence of speed on noise and summarized that noise level increased about $0.3 \mathrm{dBA}$ per mile increase of vehicle speed. This phenomenon is independent of vehicle types and reference tire type. Similar observation was also made by Wang et al. [15] who performed tests on various types of pavement surfaces in North Carolina by using the OBSI method. Researchers concluded that noise level increases with increasing vehicle speed.

\subsection{Temperature}

Ledee and Pichaud [16] investigated the effect of temperature on tire-pavement noise for various types of pavement surface. The SPB method was used for noise measurement and air temperature varied from $5{ }^{\circ} \mathrm{C}$ to $30^{\circ} \mathrm{C}$ during noise testing. It was clear from the test results that noise level decreased with increasing temperature. About $1 \mathrm{dBA}$ reduction in noise level for every $10^{\circ} \mathrm{C}$ increase in air temperature was reported for dense bituminous pavements, while it was $0.6 \mathrm{dBA}$ noise reduction 
for porous pavements. However, a quite small noise level reduction was observed for concrete pavements. Furthermore, this study also indicated that the influence of temperature on tire-pavement noise is dependent on the frequency of noise. Rochat [17] investigated the relationship between sound level and air temperature for data sets collected for three studies: (1) the Arizona Department of Transportation (ADOT) Quiet Pavement Pilot Program (AZ QPPP) [18]; (2) the California Department of Transportation (Caltrans) Thin Lift Study [12]; and (3) the Federal Highway Administration (FHWA) Traffic Noise Model Pavement Effects Implementation Study (TNM PEI) [19]. All data sets were collected using wayside measurement techniques. Test results indicated effect of temperature on sound level can be affected by both vehicle type and pavement type. In general, sound levels slightly decrease as the temperatures increase for majority of data sets. However, there are some data sets that indicated slight increase in sound levels as the temperatures increase. The effect of temperature on sound level is more noticeable for a PCC surface followed by dense graded asphalt concrete (DGAC) and open-graded asphalt concrete (OGAC) surfaces with an exception for heavy trucks in the OGAC category which actually showed an increase in sound level with increase in temperature. This is contrary to research findings from other European studies, which showed the temperature effect is more prominent for DGAC surfaces than PCC surfaces [4,20,21]. Rochat [17] described that the PCC surfaces used in these studies were textured with longitudinally tined and diamond ground PCC and transversely tined PCC; it is possible that the higher temperature effects seen with PCC in these studies can be attributed to some of the rougher textures on these pavements. This is because studies $[4,21]$ reported that rough-textured pavement surfaces show a large effect from temperature compare to smooth-textured surfaces. Donavan and Lodico [8] also reported a clear downward trend between temperature and noise level for a Dunlop tire. In this study, the OBSI testing method was used for noise measurements and an average $1 \mathrm{dBA}$ decrease of noise level with every $10^{\circ} \mathrm{C}$ increase of air temperature was reported for both HMA and PCC surface types. It is to be noted that Dunlop tire is not standard reference test tire [22]. For the standard reference test tire [22], the trend was not prominent but still showed a downward trend with increasing temperature for both types of surfaces. Some recent studies [23-26] also demonstrated a decrease in noise levels as temperature increases. This finding of decreasing noise levels with increasing temperature is consistent and reasonable with the results reported by earlier studies.

\subsection{Aging of Pavement Surface}

Acoustical performance of pavements may change with pavement age due to traffic and environmental effects. This has been substantially documented in various studies $[2,4,6,12,23,25,27-31]$. Nevertheless, researchers [2,4] suggested a long term monitoring of pavements is required to improve the knowledge in the field. Kephalopoulos et al. [31] demonstrated that porous pavements with a low noise level had shorter acoustic lifetimes compared to dense pavement surfaces, especially for asphalt surfaces. Trevino and Dossey [32] showed that porous pavements get louder with time. Researchers hypothesized that the voids at the surface get clogged with dirt over time, and this could be the cause of the increasing sound level. The authors recommended further research of repeating the noise measurements over a long period of time in order to validate their hypothesis. Bennert et al. [6] also examined the correlation between noise level and pavement aging and concluded that noise levels increase with increasing age for the surfaces having same nominal aggregate size. Similar results were also derived in an earlier study by Nicholls [33], which demonstrated acoustic performance of pavement deteriorating with time. Arizona Department of Transportation (ADOT) used asphalt rubberized friction course (ARFC) overlaying on a PCC surface to reduce noise [34]. They collected noise data using a NCAT CPX trailer and reported that acoustical performance of an ARFC overlaying surface decreases with age. Another study conducted by ADOT [35] used both OBSI and wayside noise measurement system to identify the acoustic longevity of ARFC surface. Test data indicated that noise level increases for about $0.7 \mathrm{~dB}$ per year for this ARFC surface. Recently, Tehrani [36] summarized from a number of research articles that noise benefit of ARFC surface decreases with age. This is the 
main reason for the Federal Highway Administration's (FHWA) reluctance to accept surface type as a noise abatement option, because acoustical benefits of these low noise surfaces diminished with time.

In order to evaluate the long-term performance of OGAC, Illingworth \& Rodkin, Inc. [37] (funded by Caltrans) performed noise testing for 12 years on a high volume, multi-lane portion of Interstate 80 near Davis, California. The continuous flow traffic time integrated method (CTIM) was used for pass-by noise measurements, whereas the OBSI method was used for tire-pavement interaction noise measurements. CTIM test data showed that a slight increase $\left(\sim 1 \frac{1}{2} \mathrm{dBA}\right)$ in noise levels after 10 years. However, over 12 years, traffic noise levels for the OGAC overlay using the CTIM method increased by about $3 \mathrm{dBA}$ (as shown in Figure 3). They reported that this rapid increase in noise level $\left(\sim 1 \frac{1}{2} \mathrm{dBA}\right.$ ) over the last two-year period is due to pavement raveling. A similar trend was also observed with OBSI test data in which noise level increased for $2 \mathrm{dBA}$ for the first 10 years and then increased about another $2 \mathrm{dBA}$ in the last two years (as shown in Figure 4).

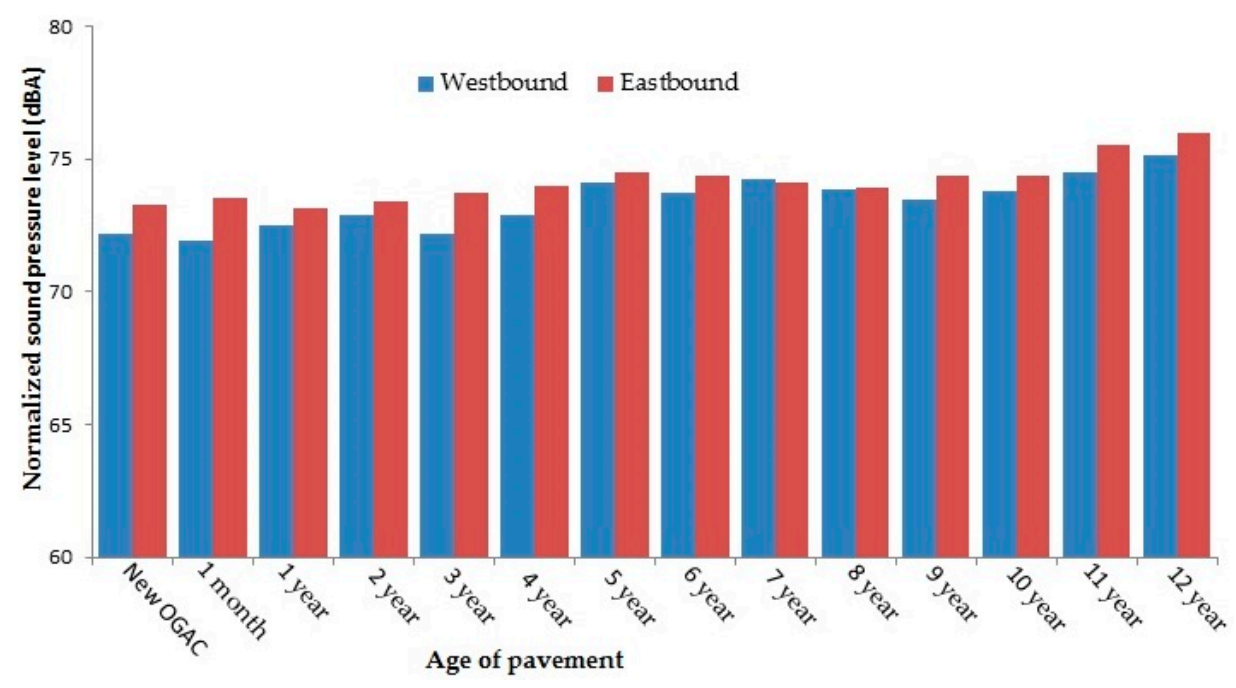

Figure 3. Changes in sound pressure level with time [37].

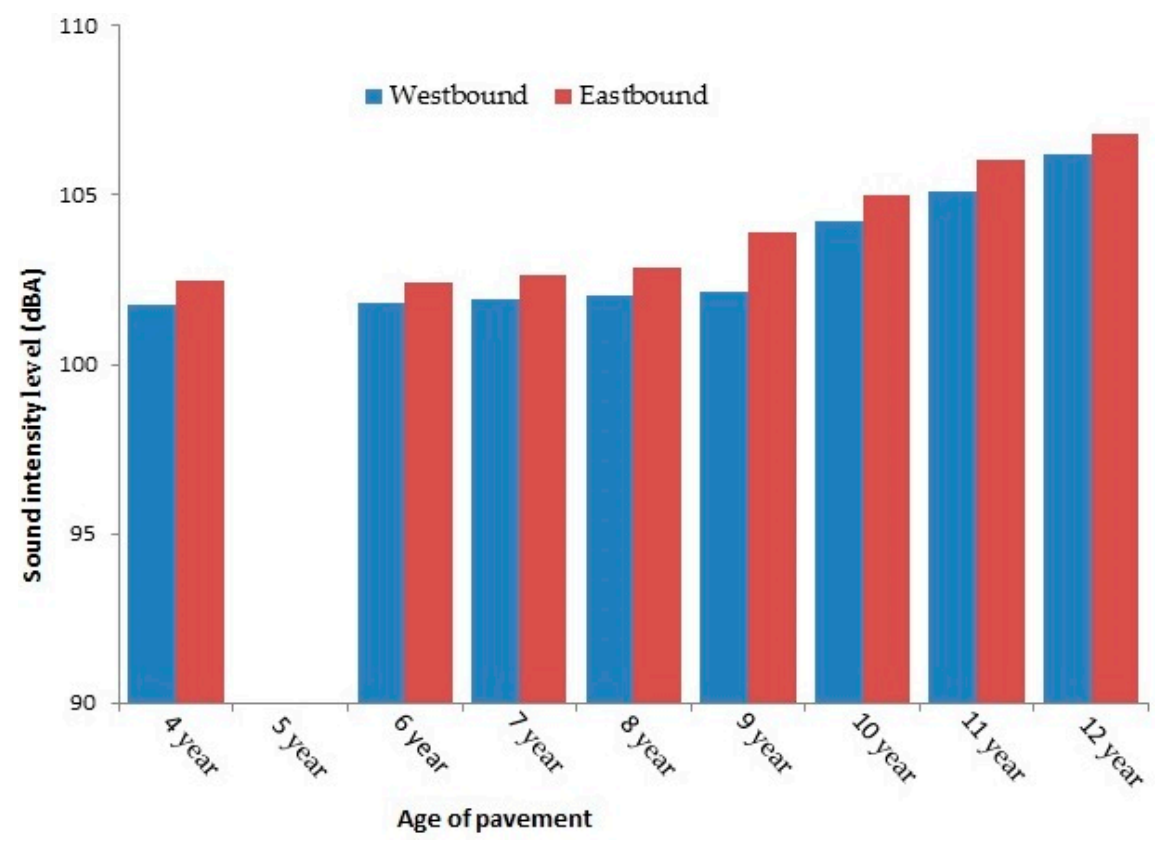

Figure 4. Changes of on board sound intensity (OBSI) levels with time [37]. 
Hanson and Waller [38] conducted comprehensive noise testing on both HMA and PCC pavement surfaces in the state of Colorado by using the NCAT CPX trailer. After three years of data collection, it was reported that noise levels of the tested pavement increased slowly with age. This is in line with the earlier studies by Hanson et al. [39] and Sandberg [40] which indicated that noise might increase by some level when the pavement is aged. More profound evidence of increasing noise level with time has been reported by Rasmussen and Sohaney [41], who performed OBSI noise testing on 34 pavement sections, which are currently used by Colorado department of transportation (CDOT). They indicated an average $0.2 \mathrm{dBA}$ increase of noise level per year without considering traffic volume and its associated wear on pavement. This finding is further validated by number of recent studies [26,42].

\subsection{Maximum Aggregate Size and Gradation}

Numerous research studies have been conducted to isolate the influence of maximum aggregate size on noise mitigation when dealing with highway traffic noise. Kowalski [43] used a laboratory testing apparatus called the tire-pavement testing apparatus (TPTA) to evaluate the effect of aggregate size on noise properties of asphalt pavements. The TPTA has a fixed drum rotating on a fixed circular plate that has a diameter of $4.1 \mathrm{~m}$. The test specimen is about $1 / 6$ th of the circumference. This apparatus has two main limitations. First, the maximum speed of the rotating wheel is $48 \mathrm{~km} / \mathrm{h}$. The speed is less than the typical speed of highway traffic, due to a few technical problems such as the large centrifugal forces created at the arm. Second, preparation of the laboratory test specimen is a complicated process. The laboratory experiments were only partially successful due to the difficulties in compacting asphalt mixtures such as PFC (porous friction course) mixtures in the convex mold used in the experiment. The near field noise measurements were used to measure the noise on the TPTA. In general, the results showed that the mixtures with $19 \mathrm{~mm}$ nominal maximum aggregate size (NMAS) have a higher noise level compared to $9.5 \mathrm{~mm}$ NMAS mixtures. The European Asphalt Pavement Association [29] summarized the test data of Laboratoire Régional des Ponts et Chaussée in France [44] and reported that a difference of more than $10 \mathrm{dBA}$ was observed between fine grained porous surfaces and porous surfaces with a large maximum aggregate size. Furthermore, these data indicated that a larger maximum aggregate size is generally associated with higher noise levels. The same trend was observed for all types of surfaces, i.e., asphalt surface, concrete surface with different types of slurry seal or surface dressing. Donavan [45] summarized test data from four European Countries and reported about $7 \mathrm{dBA}$ increasing of sound intensity level for coarse graded DGA surface in comparison with fine grained DGA surface, as shown in Figure 5. Similar trends also followed for SMA surface as shown in Figure 6.

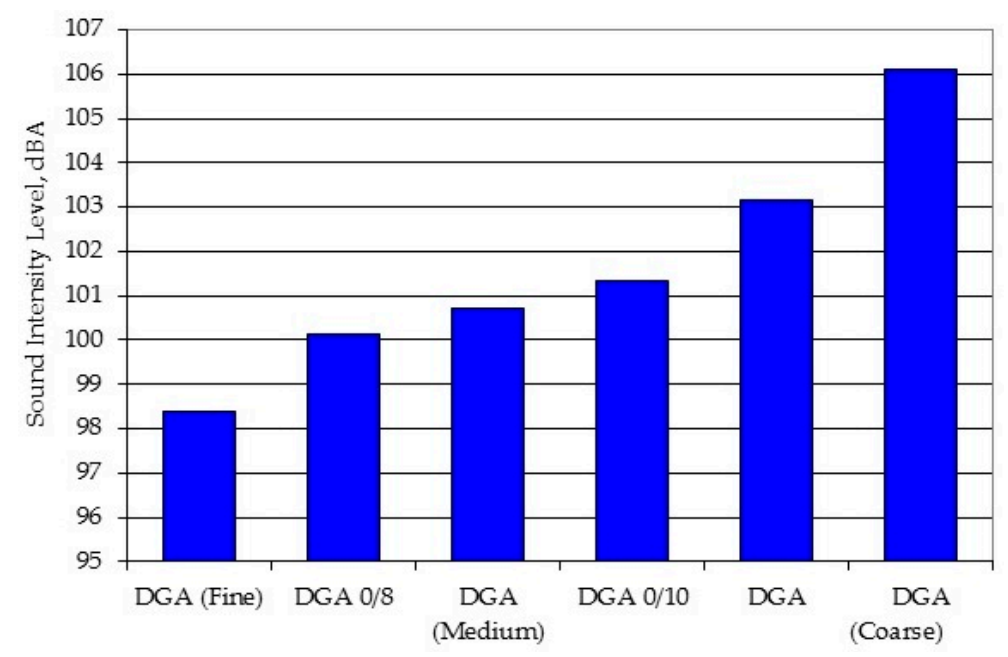

Figure 5. Noise performance of dense graded asphalt (DGA) pavements of varying aggregate size for four European countries [45]. 


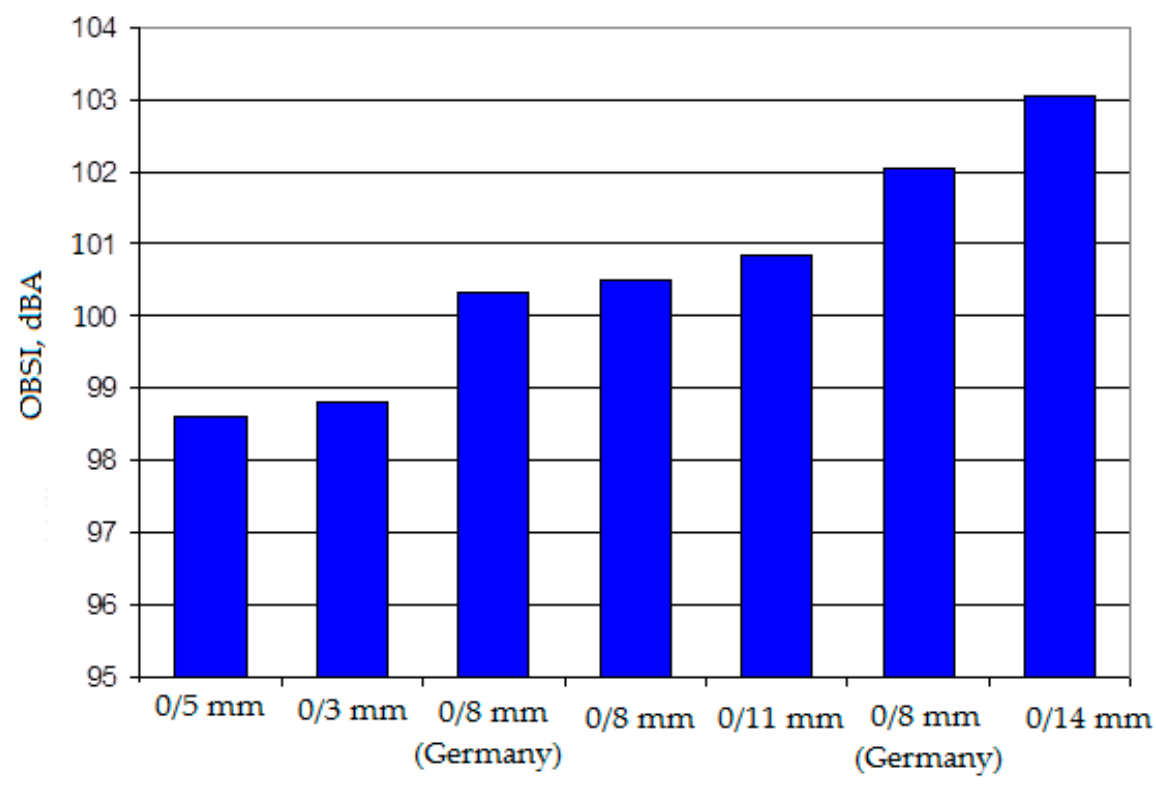

Figure 6. Noise performance of stone mosaic asphalt (SMA) pavements of varying aggregate size for four European countries [45].

Timm et al. [46] also observed lower levels of tire-pavement noise for fine graded pavement surfaces in comparison with those with coarse graded surface. Sousa et al. [47] demonstrated that a tire will be exposed to less deformation for smaller aggregate sizes, thus the air entrapped between the tire and pavement will face less squeezing resulting in less pressure change and thus generate less noise. An earlier study conducted by Meiarashi et al. [48] also observed noise reduction in drainage asphalt roads with decreasing aggregate nominal size. Significant noise reduction was noted when they changed the maximum aggregate size from $13.0 \mathrm{~mm}$ to $10.0 \mathrm{~mm}$. The same study also concluded that the diameter of the aggregate plays a critical role in the reduction of traffic noise. Many studies $[4,6,39,49,50]$ also suggested that one of the conditions to a low noise pavement is having a smooth surface using small aggregate maximum size.

A number of publications indicated $[4,49]$ that the pavement surface texture (microtexture and macrotexture) is affected by the aggregate maximum size, and that the latter has an effect on noise mitigation.

Hanson et al. [39] conducted a study to understand the influence of aggregate gradation on tire-pavement noise by using the NCAT CPX trailer. Researchers found that the open-graded asphalt mixtures with coarse aggregate gradation produce more noise than those of dense-graded asphalt mixtures. The open-graded asphalt mixture with finer aggregate gradation was the quietest pavement among those evaluated in the study. This is further validated by Hanson and Waller [38] who performed noise testing on 12 HMA surfaces in the state of Colorado. A similar CPX testing method was used for the noise measurements, and test data indicated that coarser gradation produces higher noise. Sandberg and Ejsmont [4] stated that fineness modulus, which is generally used for design of cement concrete, can be used as an indicator of gradation. Therefore, a higher fineness modulus represents a coarser aggregate mixture, which produces more noise $[4,39]$.

\subsection{Air Void Content}

Hanson and Waller [38] reported that sound absorption increased with increasing air void content for open-graded friction course (OGFC) surfaces. However, for DGA surfaces, a small correlation exists between air void content and noise level. Ongel et al. [51] observed that a typical porous asphalt surface (air void content $10 \%$ to $20 \%$ ) generates up to $4.5 \mathrm{dBA}$ less noise compared to a dense HMA surface. The same conclusion is drawn by a number of other research studies $[4,5,29,38,39,52,53]$. 
Researchers explained that noise is reduced for higher air void content due to two mechanisms. Firstly, the air trapped between the tire and the pavement surface moves to void space available within the porous surface, which in turn reduces the horn effect of noise amplification. Secondly, it provides increased sound absorption capability, which in turn reduces noise $[4,39]$. However, there is always a concern that the surface of these high porosity surfaces is often exposed to clogging with dirt. The process of clogging accelerated on the road of less important. At lower vehicle speeds, the pores of the surface are consistently filled up by fine particles due to passing wheel. This is because there are no adequate facilities to cleaning the surface. This reduces noise benefit of these surfaces. To avoid these problems, European researchers recommended using two layer systems [54].

\subsection{Surface Type}

Pavement surface type plays an important role in how it generates noise at the tire-pavement contact point $[4,41,45,55-60]$. Meiarashi et al. [48] measured noise levels for both porous and dense asphalt surfaces for various types of vehicle. They observed that noise levels reduced for porous asphalt surface 1.0 to $7.0 \mathrm{dBA}$ for cars, 3.0 to $4.0 \mathrm{dBA}$ for light trucks, and 4.0 to $6.0 \mathrm{dBA}$ for heavy trucks in comparison with the dense asphalt surface. Some research studies $[6,61]$ indicated that the addition of crumb rubber could increase the sound absorption capacity, which in turn reduces noise. However, Shatanawi [62] reported crumb rubber does not directly affect sound absorption but changes its mixture properties such as permeability and, binder content which have effect on pavement noise. Sousa et al. [47] also reported that asphalt rubberized OGFC is the quietest surface. A number of recent studies [36,63-66] showed that OGFC produce less noise compared to conventional HMA and PCC surface. Of them, Tehrani [36] concluded from a number of research projects that addition of rubber decreases noise level about 2 to $3 \mathrm{dBA}$ compared to HMA surface and 4.5 to $6 \mathrm{dBA}$ compared to PCC surface. Researcher argued that addition of rubber to pavement mix tends to shift the frequency of noise to the lower frequency, which is close to tire noise. Therefore, rubber does not resonate at high frequency thus limits the amplification of noise mechanism which in turn reduces noise.

Bennert et al. [6] evaluated acoustic performances of both asphalt and concrete surfaces using the CPX method. The asphalt pavement included different mixtures, and the concrete pavements had different surface treatments. The results showed that the open-graded asphalt mixtures, especially the ones modified with crumb rubber, had a low noise level compared to dense-graded mixtures. The concrete transverse tined surfaces had the loudest noise levels, while diamond grinding pavement surfaces had the lowest noise levels. The concrete diamond-ground surfaces had a noise level comparable to asphalt pavements. It was also concluded from this study that concrete surfaces generated more noise compared to asphalt pavements. Rasmussen and Sohaney [41] conducted a recent study to evaluate the tire-pavement noise and long-term acoustical durability of various pavements in Colorado. The researchers measured the tire-pavement noise using two different techniques: CPX and OBSI. The results showed that each pavement type demonstrated a wide range of noise levels, and there was a strong overlap. In addition, it was not possible to identify a single pavement type that provides the lowest level of tire-pavement noise. The researchers also found that asphalt pavements constructed using crumb rubber had the lowest noise when newly constructed. However, the noise levels of crumb-rubber pavements increased with the time and were comparable to other pavement types evaluated in this study. Rasmussen and Sohaney [41] recommended more investigation of alternative asphalt mixtures and concrete textures that produce low tire-pavement noise.

Parnell and Samuel [67] investigated the noise generation of 20 pavement surfaces, which included both HMA and PCC surfaces in the state of New South Wales, by using a pass-by noise measurement technique. They presented that HMA surfaces produce less noise compared to concrete surfaces. It was explained that noise level of a particular pavement is significantly influenced by the orientation of texture. HMA pavement has a random texture, which is similar in all directions, and can be considered isotropic. PCC pavement with horizontal and transverse tinning has mostly periodic texture, which in turn results in a number of air displacement mechanisms such as air pumping 
and pipe resonances [4]. Parnell and Samuel [67] also reported that a transverse tinned surface produces higher noise in comparison to other types of concrete surfaces. The difference in noise level between various PCC concrete surfaces is due to the surface texture. Based on the results of many research studies, Sousa et al. [47] also identified that transverse tined concrete as the noisiest surface, while diamond ground concrete pavement was the quietest among concrete pavements. Similar findings were also observed in a New York State Thruway Authority and FHWA Pavement study [23]. Donavan [45] performed a comparative study on European countries PCC surfaces and California/Arizona PCC surface and noise testing was conducted by using OBSI method. Test data showed that diamond ground is the quietest surface while random transverse is noisiest surface as shown in Figure 7.

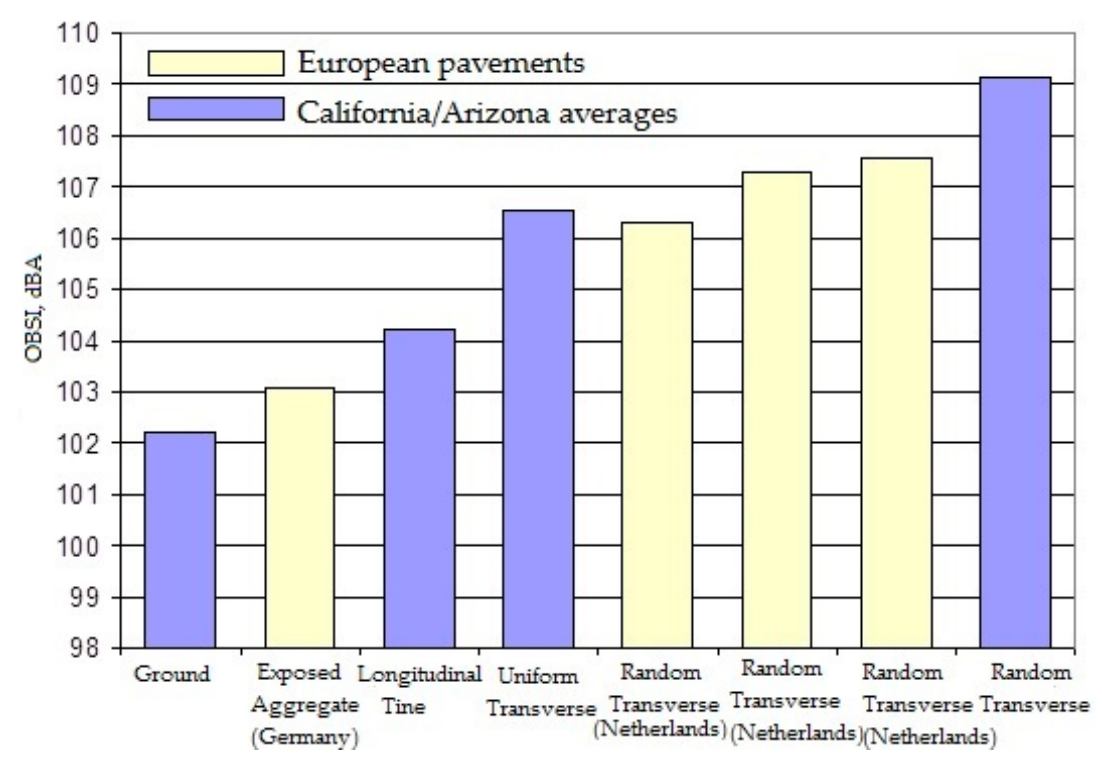

Figure 7. Overall sound intensity level for European random transverse textured and ground Portland cement concrete (PCC) pavements and the average of groupings from the California/Arizona [45].

Izevbekhai [55] performed a large number of OBSI tests on concrete surfaces in the State of Minnesota. Noise testing was conducted on surfaces which included transverse tine, traditional grind, innovative grind, ultimate grind, exposed aggregate, and transverse drag surface. It was found that transverse tine is the noisiest surface, whereas innovative grind is the quietest surface.

\subsection{Surface Texture}

Pavement texture plays an important role in enhancing friction, especially in wet weather conditions. Furthermore, the mechanisms of tire-pavement noise are significantly affected by pavement surface texture. Surface textures change after construction under the actions of traffic, environment and the interaction of the two, referred to as the aging of the textures [68]. A comprehensive study by Bernhard and Wayson [49] showed that negative texture with characteristic length less than $10.0 \mathrm{~mm}$ tends to reduce noise. However, texture of other sizes and types tends to increase noise.

At high frequencies (frequencies above $1000 \mathrm{~Hz}$ ), microtexture (wavelength less than $0.5 \mathrm{~mm}$ ) has been shown to affect tire-pavement noise $[4,69]$. Microtexture may affect high-frequency noise generation mechanisms such as stick-slip and stick-snap by changing the contact conditions between tire and pavement. However, macrotexture (wavelength between $0.5 \mathrm{~mm}$ and $50 \mathrm{~mm}$ ) has been shown to affect OBSI levels in the 630-1000 Hz range [70-72]. Macrotexture can change the volume of air cavities thus affecting the air pumping and pipe resonance mechanisms. It can also affect the impact, friction, and adhesion mechanisms. 
Abo-Quadis [73] performed a series of skid resistance tests by using the British (Pendulum) Skid Resistance Tester (BSRT) and showed that in general, an increase of the microtexture depth causes the tire-pavement noise to decrease. However, a study by Gardziejczyk and Berengier [74] reported increase of traffic noise with increasing macrotexture depth. An early study by Sandberg [40] reported that there is a strong correlation between road noise level and the road texture. However, this correlation can be positive or negative depending on frequency level. He further stated that it is not possible to generalize and say that a rougher texture means a higher A-weighted noise level. At low frequencies, the noise level increases with texture while noise decreases with texture for high frequencies. A similar relationship between noise and texture for asphalt pavement has also been observed by later studies conducted by Hanson et al. [39] and Donavan and Rymer [5].

\subsection{Aggregate Type}

Aggregate type does not have a direct impact on the development of highway traffic noise, thus very few studies have addressed the issue [4]. Nevertheless, aggregate type has impact on the microtexture of surface which in turn affects traffic noise as discussed in the aforementioned paragraph [75]. Furthermore, Huang et al. [76] suggested that binder produce different thickness of film depending on the aggregate type, which may affect traffic noise.

\subsection{Thickness of Pavement Surface}

A number of research studies $[4,39,48,62,77]$ suggested using a thick porous pavement to reduce the generation of traffic noise. Rochat and Read [78] suggested that if a porous surface is not thick enough, sound reflects from the underlying non-porous pavement structure and can degrade the sound absorption properties of the pavement. This was in line with the study conducted by Rochat et al. [57]. They performed OBSI noise testing on NCAT test tracks. Noise testing was conducted on two surfaces having similar properties (i.e., aggregate size, percent air void, and pavement type) but different thickness. Test results showed that thicker pavement was $4 \mathrm{dBA}$ lower in sound intensity level then pavement with less thickness. Sandberg and Ejsmont [4] related the thickness of pavement to the air flow resistance if high thickness pavement is desired. Moreover, the thicker pavements perform at higher porosity for a longer time in operation (as compared to thinner layers), because more dirt accumulating in its pores is required before it is clogged.

\subsection{Stiffness of Pavement Surface}

Stiffness of a pavement surface is the one of the main structural design parameters, but its contribution in generating tire-pavement interaction noise is less significant [40]. The general hypothesis is that the influence of various noise generation mechanisms can be minimized by using pavement stiffness similar to the stiffness of the tire [2]. This hypothesis is used on experimental pavements containing epoxy-bound shredded rubber termed Poroelastic surface, which reduced noise significantly. When a rolling tire impacts the pavement surface, the noise generation may amplify or attenuate depending on the stiffness of road [40]. This may imply that concrete pavement is nosier in comparison to a HMA surface because stiffness of concrete pavement is higher than that of the HMA pavement. Sousa et al. [47] compared the data from various studies and showed that stiffness of pavement appears to have an effect in noise generation. However, Descornet [52] reported that effect of stiffness on tire-pavement interaction noise is still a contentious issue.

\subsection{Effect of Sound Absorption on Tire-Pavement Noise}

When a sound wave strikes the surface of a material, some of the acoustic energy is reflected and the rest is converted to heat and absorbed. The human ear generally hears the reflected part of the sound wave (in addition to the direct path between the sound source and the ear). The sound absorption ability of an acoustic material is generally indicated by the absorption coefficient [79]. A few studies have been conducted to evaluate the effect of pavement type and mix design on the 
absorption coefficients of pavements and the potential correlation with the absorption coefficients with tire-pavement noise $[10,51,57,62,80-84]$. These studies indicated that the absorption coefficient is an important property of a road surface which influences the noise level generated on roads. Ongel et al. [51] measured the absorption coefficients of asphalt cores extracted from different types of pavements using an impedance tube, while the OBSI method was used for noise measurements. It is observed from the compared data that at lower frequencies (frequencies less than $1000 \mathrm{~Hz}$ ), sound intensity level decreases with increasing absorption values for dense and gap-graded mixes. However, for open graded mixes, higher absorption values do not necessarily decrease the noise at lower frequencies, because texture of this mix dominated the noise generation. For frequencies above $1000 \mathrm{~Hz}$, tire-pavement noise reduces with higher absorption values for gap-graded mix pavements. The findings of this study were confirmed by another study conducted by Leung et al. [10]. Researchers found that open-graded asphalt mixtures provided the highest amount of sound absorption ability compared to dense-graded and stone matrix asphalt mixtures over a frequency range of $400 \mathrm{~Hz}$ to $1000 \mathrm{~Hz}$. This study also recommended additional noise measurements to be collected to evaluate the pavement acoustical performance over time. Nelson et al. [85] measured both the acoustical absorption coefficient and sound intensity level of 140 pavement sections. The sound absorption coefficient was measured by using an impedance tube, whereas the sound intensity levels for the corresponding sections were measured in the field. They summarized that the correlation between sound absorption coefficient and sound intensity level is depended on the frequency of sound for an OGAC surface. For frequencies of $500 \mathrm{~Hz}, 630 \mathrm{~Hz}$, and $800 \mathrm{~Hz}$, sound intensities are shown to increase with an increase in sound absorption. For $1250 \mathrm{~Hz}$ and $1600 \mathrm{~Hz}$, sound intensity levels decrease with increase in sound absorption. Nevertheless, researchers did not find any correlation between sound intensity level and sound absorption at the frequency of $1000 \mathrm{~Hz}$. For dense-graded and gap-graded asphalt surfaces, sound intensity decreases with an increase in sound absorption over all frequency bands.

Rochat and Read [78] suggested effective flow resistivity (EFR) can be used as a measure of sound absorption of pavement. They collected EFR data for a variety of pavements by using a modified version ANSI S1.18 [86]. Data indicated that lower EFR values for the pavements (more absorptive) attributed to the porous and open graded surface whereas higher EFR values are obtained for thick dense pavement (more reflective). This is in line with the reported literature that showed porous pavements being less noisy compared to dense pavements.

Kumar et al. [81] compared sound absorption coefficients of various asphalt and concrete pavements. The researchers used an impedance tube to measure absorption coefficients at different frequencies. It was found that the average sound absorption coefficients for asphalt pavements were 39.13 percent lower (more absorptive) than the ones measured on concrete surfaces. Sachakamol and Dai [87] developed an analytical procedure for predicting the sound absorption coefficients of porous asphalt pavement. The researchers concluded that the porosity has significant influence on the absorption coefficients, while the layer thickness has an insignificant impact on the absorption coefficients. Asphalt mixtures made with rubber materials had improved absorption characteristics over a wide range of frequencies. The model prediction of absorption coefficients had a good match with the measured values in the laboratory. Raimundo et al. [88] examined the absorption coefficients of wet gap-graded asphalt mixtures with different levels of air void content and rubberized asphalt bitumen. Wet samples had lower sound absorption coefficients than samples in dry conditions. In addition, samples with high porosity had higher sound absorption coefficients compared to samples with less porosity.

\subsection{Effect of Surface Friction on Tire-Pavement Noise}

Several aspects of pavement surface characteristics should be considered for proper designing and functioning of pavements. This can be divided broadly into three categories: safety related issues (skid resistance/friction, splash and spray, visibility of the road and markings, and tire grip qualities); economic considerations; and user and residents' comfort as related to noise and vibration inside 
and outside the vehicles [89]. Friction between the tire and pavement surface plays a critical role in enhancing the road safety. Generally, the skid resistance index is used in describing the level of frictional force of the pavement surface. Therefore, it is necessary to understand the influence of skid resistance on the generation of traffic noise. Common hypothesis suggests that the skid resistance of a pavement surface increases with increasing surface texture, which in turn increases tire-pavement interaction noise. However, Ahammed and Tighe [90] reported that some texture (skid resistance) is required for lower noise. Therefore, the relationship between friction and tire-pavement interaction noise is not straightforward.

Franklin et al. [91] conducted a pass-by noise and skid resistance test on 34 surfaces in the UK. Various surface types (brushed and grooved PCC, rolled AC and surface dressing) were included in this study. Test data showed that pavement noise is a function of both texture depth and surface types. Researchers also observed that correlation between skid resistance of pavement and speed of the vehicle is dependent on surface type. For some surface types, skid resistance increases with any increase of vehicle speed while decreases for others. Therefore, the correlation between pavement friction and noise is not consistent because it is a well-established correlation that noise increases with increasing vehicle speed irrespective of surface types. Jaeckel et al. [92] also performed a number of tests on both PCC and HMA surfaces and observed no conclusive relationship between noise level and skid resistance. Wielen [93] performed both tire-pavement interaction noise and skid resistance tests on 25 PCC pavement surfaces in South Africa. A pass-by method was used for noise testing. They observed that noise increases with increasing skid resistance value for small passenger cars. However, for trucks, no correlation exists between surface noise and skid resistance.

Schlaefer and LaForce [94] measured both pavement noise and skid resistance of four pavements in Colorado. For noise testing, a pass-by method was used, and test pavement sections included three PCC surfaces (longitudinal tinned, transverse tinned and deep ground PCC) and one HMA surface. Test results showed that the HMA surface is the quietest among the four surfaces and also had the highest skid resistance value. This was contrary to an early study conducted by Kuemmel et al. [95]. In this study, both noise and skid resistance tests were performed on 57 pavement surfaces (both PCC and HMA) in six states in the USA. Both roadside and in-vehicle noise tests were conducted for this study. The study indicated that the HMA surface is the quietest and transverse tinned PCC was loudest among all the surfaces, while skid resistance data showed that the PCC surface had higher skid resistance compared to the HMA surface.

A number of recent studies [51,96-98] have shown that there is a correlation between pavement noise and skid resistance. In general, the trend showed that tire-pavement noise and skid resistance value is negatively correlated, i.e., increased safety is associated with an increased (undesirable) noise. The conflicting research outcome reported in literature is probably due to the fact that friction is related to surface texture. As discussed in the aforementioned surface texture section, surface texture may have positive or negative effect on the generation of noise depending on the frequency of noise.

\section{Noise Prediction Models}

One of the main objectives of highway noise research is to develop a consistent, accurate model so that transport authorities are able to predict highway traffic noise. In addition to predicting highway traffic noise, there are also models for predicting tire-pavement noise. Therefore, a number of noise prediction models have been proposed by various researchers throughout the world. For proper understanding of a noise prediction model, it is essential to know how the input parameters are measured and how changes in pavement design parameters can affect the input data for noise prediction models [25]. In this section, some of the well-known noise prediction models found in the literature are discussed in detail.

An early model developed by Kugler et al. [99] correlates traffic parameters (traffic volume, vehicle speeds and types), sound propagation parameters (distance between source and observer) and road abatement parameters in order to predict sound pressure levels in the vicinity of the highway. 
Although this model did not consider pavement surface characteristics, the difference between actual and predicted value was found to be within $\pm 2 \mathrm{dBA}$. Wayson et al. [100] proposed the Community Noise Model (CNM), which is similar to the Kugler et al. [99] model. In this model, the input data are: traffic volume, vehicle speed and type, surface type, ground effects and barrier attenuation. Though the model showed good correlation between measured versus predicted results, it did not consider surface characteristics. Pavement characteristic is one of the main contributors in highway-generated noises, and therefore research continues to incorporate it in noise prediction models.

Nordic countries (Sweden, Denmark, Norway, Finland and Iceland) introduced a common model in the 1970s for prediction of traffic noise. This Nordic Model underwent several modifications and was commonly adopted as TemaNord at 1996 for all the Nordic countries [101]. This method gave accurate noise predictions compared to other methods. The main reason is that it included detailed road surface corrections. The addition of road surface corrections encourages the construction of surfaces that give lower traffic noise. However, this model does not give separate surface effects for cars and trucks directly but provides surface effects for mixed traffic. The reference surface was based only on an HMA surface. The latest version of the Nordic model is called Nord2000 [102]. In this model, surface corrections for road categories are also included.

A number of researchers $[103,104]$ presented an empirical relationship between texture level and noise level for asphalt pavement surfaces. However, modeling was limited to only asphalt surfaces. Rasmussen [105] developed a statistical model based on the effect of pavement texture. In this model, the input data for a 3D texture profile were captured by the RoboTex line laser profiler while noise measurement was performed by using the OBSI method. For each type of pavement texture, a number of sections were included in the analysis. A standard error of $0.6 \mathrm{dBA}$ was reported without presenting specific number of pavements used and the range of their OBSI levels. A similar statistical model was developed by Fujikawa et al. [106] in which a laser profiler is used to measure surface profiles. Nonetheless, this model predicts mean square acoustic pressure instead of decibel sound pressure or intensity as used by the Rasmussen [105] model. Input data for this model were collected from nine pavement sections which include six dense-graded asphalt pavements, two open-graded asphalt pavements and one polished surface. The difference between measured and predicted noise values was observed within $2 \mathrm{dBA}$ for all frequency bands.

Reyes and Harvey [107] employed a different approach for developing a model in which the input parameters are given from laboratory pavement core samples and not from field test sections. The input parameters are mean profile depth (MPD) and airflow resistivity. Both these parameters were collected from laboratory core samples. Since the input parameters were collected from the laboratory controlled environment, they are less influenced by environmental conditions. A total of 16 different cores, which included open graded and gap graded asphalt pavements, were used for statistical input parameters. This model is one of the very few models where prediction of one-third octave band frequency data can be done. Although no standard error was provided for predicted noise, but it presented a low coefficient of determination which generally has a high influence on overall OBSI levels.

A number of researchers [108-114] attempted finite element and boundary element modelling methods to predict tire-pavement noise. Of them, Roo et al. [112] developed the Tyre-Road Interaction Acoustic Simulation (TRIAS) model, which is a purely physical model to predict tire vibration and noise emission. The various parts of this model were validated by number of later studies [110-114]. There are two sub-models under this model. One is the Road Design Acoustic Simulation (RODAS) model, which generates the physical road surface characteristics (texture, porosity and sound absorption) from the material composition (aggregate size, binder content and layer thickness). The other sub-model is known as TYDAS (TYre Design Acoustic Simulation), which simulate model inputs from known tire parameters. This model is validated in both porous and dense surfaces and ISO test tracks by pass-by noise measurement methods. The predicted value was within $2 \mathrm{dBA}$ and $5 \mathrm{dBA}$ for dense and porous surfaces, respectively. 
The U.S. Department of Transportation FHWA developed the Traffic Noise Model (TNM) to predict noise levels in the vicinity of highways [115-117]. TNM is extremely important in the USA because it is required to determine whether noise barriers are needed in Federal funded projects [32]. This model includes three very general pavement categories, but an average pavement is required for noise impact predictions. For TNM v1.0, Burge et al. [118] compared field results of longitudinally ground and transversely tined concrete pavements. They reported that similar relationships exist for both types of pavements using measured and theoretical values. As this tool continues to evolve, validation would be highly desirable. Prior to release of TNM v2.5, a TNM validation study showed an average over-prediction of sound levels for a variety of pavement types. TNM v2.5 addressed the over-prediction issue, and a validation study showed good agreement on average between measured and predicted data [78]. The study directly compared predicted sound levels to measured sound levels for both calibrated and uncalibrated data (where site bias has not been removed). For calibration, a reference microphone was located at a distance of $15 \mathrm{~m}$ from the center line of near travel lane and $1.5 \mathrm{~m}$ above the roadway elevation for open area whereas for barrier sites, a microphone was placed at $1.5 \mathrm{~m}$ above the top of the barrier or off to the side of the barrier $1.5 \mathrm{~m}$ above the roadway section. Result showed TNM v2.5 performed extremely well for both calibrated and uncalibrated data due to improvements applied to the implementation of emission level. However, there is some site bias such as pavement type that can affect the prediction of sound level [119]. More recently, U.S. Department of Transportation/Volpe National Transportation Systems Center [57] conducted a pavement effect implement (PEI) study under FHWA sponsorship to incorporate a broad range of pavement effects in the TNM model. FHWA TNM v2.5 was modified for research purposes to incorporate pavement effects. In FHWA TNM v2.5, two sound sources are used to describe vehicle noise each vehicle type, with the lower-height source representing tire-pavement interaction noise. In this special version of FHWA TNM v2.5, the lower source is isolated and adjustments due to pavement effects have been applied in the calculations for each one-third-octave band. Researchers compared the measured and predicted noise level for three surfaces, which include open graded rubberized asphalt, longitudinal tinned PCC and transverse tinned PCC. Results show that pavement-adjusted spectral shapes match more closely to measured spectra which indicated pavement effects can be incorporated in the FHWA TNM model by using an OBSI adjustment to the tire-pavement sub-source. However, there are some limitations of this modified TNM version as it is validated only for one type of car test tire therefore it is not fully representative for all vehicles and tire types of road. TNM version 3.0 is currently under development; this version will include only the three original pavement categories, and again the average pavement is required for impact predictions. A research version that allows for pavement adjustments will not be available with the release.

Izevbekhai [55] provided a robust model where OBSI noise can be predicted based on pavement surface parameters, pavement ride comfort, and climatic factors. The model is validated with OBSI data. This model was also applied for quieter pavement design in two rehabilitation projects. The measured OBSI values were observed to be within $1 \mathrm{dBA}$ of predicted values. In this model, International Roughness Index (IRI) is used to predict OBSI data. Test data showed that OBSI increased with increasing IRI value. This model showed that variations of IRI due to seasonal variations may have a trivial effect on the ride quality measurement, but it has significant influence on the generation of pavement noise. This model also showed that mean profile depth (MPD) may not have significant correlation to OBSI data as opposed to previously established correlation between MPD and OBSI. This model also included texture asperity interval in order to predict tire-pavement noise. Predicted and measured noise data showed that OBSI values decrease with increasing texture asperity interval. However, this model is validated only using a limited amount of data. In fact, data used for this model validation are measured on MnROAD test sections only.

Recently, Dare et al. [25] suggested the use of a mechanism decomposition approach for prediction of tire-pavement noise on asphalt pavements. In this approach, noises from different mechanisms at certain frequencies are modeled separately and then combined to form a total noise spectrum. This is 
particularly important for pavement noise as there are a number of parameters that affect the noise. In this study, two nonlinear statistical models were developed, which were used for prediction of one-third octave bands and overall sound intensity levels on asphalt-surface pavements. The effects of most of the important pavement parameters (i.e., pavement macrotexture, air temperature, modulus of the pavement surface layer) in generation of noise are incorporated in this model. The input data for the model are collected from 25 asphalt road test sections, which include different mixtures and materials at various locations of Minnesota Department of Transportation. The model predicted the overall OBSI (sound intensity) level to within $1.5 \mathrm{dBA}$ and the one-third octave bands to within $2 \mathrm{dBA}$ for most of the pavements tested. The other advantageous feature of this model is that it is configured in such a way that any future addition/refinement can be made, if required.

\section{Future Research Direction}

A literature survey showed that considerable progress has made in several aspects of mitigating tire-pavement interaction noise. However, some areas of designing quieter pavement are not still properly addressed. Some of the debatable issues are discussed below:

1. Various factors affected the tire-pavement noise as reported in literature. Of them, temperature plays an important role in generating tire-pavement noise. The literature survey showed that the highest air temperature used in previous studies is limited to $95^{\circ} \mathrm{F}$ [17]. Donavan and Lodico [120] conducted a study on precision and bias of OBSI testing (which is the basis of current AASHTO standard) and restricted temperature for noise testing within 20 to $100^{\circ} \mathrm{F}$. However, in some regions especially in the Middle East, temperature often exceeds $100^{\circ} \mathrm{F}$ during summer time. Therefore, a comprehensive testing program incorporating a wide range of temperatures is needed to evaluate the temperature effect on tire-pavement noise.

2. Porous pavement is widely accepted as a low noise surface. However, researchers hypothesize that the voids of this surface fill with dirt over time, which in turn increases noise. This is particularly important in the Middle East region, where large amounts of dirt are present in atmosphere. Therefore, a systematic laboratory experimental program is needed to evaluate the clogging effect on the noise properties of the mixtures.

3. The literature survey also suggests that there is a potential correlation between acoustic absorption properties measured in the laboratory and tire-pavement noise measured in the field. Some research studies have been performed to validate this relationship but observed conflicting trends. Therefore, a comprehensive evaluation of the relationship between acoustic absorption characteristics and tire-pavement interaction noise has to be conducted, which will assist engineers to optimize the design and material selection of roadway construction in order to provide a low level of road noise.

4. Surface friction of a pavement is a key safety issue. In general, tire-pavement noise and pavement surface friction appears to be inversely related. Therefore, more research is needed in order to optimize these two conflicting pavement properties.

5. Traditionally, noise prediction models have been developed by using a reference pavement (either a national average or standard pavement type) in order to predict noise impacts and determine abatement measures. Recent research showed the contribution of pavement effects on noise prediction can be incorporated in noise models. For the FHWA TNM, further work is needed to incorporate a broad range of pavements into the model.

\section{Conclusions}

Literature surveys showed that tire-pavement noise is influenced by a number of factors. Some factors influence noise generation individually while some combined with others in generating and enhancing tire-pavement noise. Of them, pavement surface types play an important role in generation of tire-pavement noise. Generally, HMA surfaces produce less noise compared to PCC surfaces. OGFC 
surfaces are the quietest among HMA surface types. While transverse tinned is the loudest and diamond grooving is the quietest surface within PCC surface types. It is evident from the literature review that acoustical performance of pavement diminishes with aging especially for porous HMA surfaces. Therefore, long term monitoring is needed to build quieter pavement that will maintain noise benefits over time. It is recognized in the literature that tire-pavement noise can be correlated to the pavement's material characteristics. However, limited number of research focuses in this area. Hence a systematic research program is required to gain better understanding of long term noise behavior of pavements.

Developing a traffic noise prediction model has paramount importance in order to design quieter pavements. However, as observed in the literature, various researchers adopted different approaches for predicting tire-pavement noise and traffic noise. This is further evidence of the associated complexities of prediction of tire-pavement noise. Even though researchers presented mathematical models that fit their particular data, there is a clear need of developing a more general and theoretically sound noise prediction model. This calls for more intensive research into this area in the coming years for the design of sustainable quieter pavements.

Acknowledgments: This paper was made possible by the NPRP grant [NPRP 7-110-2-056] from the Qatar National Research Fund (a member of Qatar Foundation). The statements made herein are solely the responsibility of the author.

Conflicts of Interest: The author declares no conflict of interest.

\section{References}

1. WHO. Night Noise Guidelines for Europe; Regional Office for Europe: Copenhagen, Denmark, 2009. Available online: http://www.euro.who.int/_data/assets/pdf_file/0017/43316/E92845.pdf (accessed on 12 May 2016).

2. Rasmussen, R.; Bernhard, R.; Sandberg, U.; Mun, E. The Little Book of Quieter Pavements; Report No. FHWA-IF-08-004; Federal Highway Administration: Washington, DC, USA, 2007.

3. Sandberg, U. Tire-road noise-myths and realities. In Proceedings of the Inter-Noise, The Hague, The Netherlands, 27-30 August 2001.

4. Sandberg, U.; Ejsmont, J. Tire-Road Noise Reference Book; Informex: Kisa, Sweden, 2002.

5. Donavan, P.; Rymer, B. Assessment of highway pavements for tire-road noise generation. In Proceedings of the Society of Automotive Engineers Noise and Vibration, Grand Traverse, MI, USA, 3 May 2003.

6. Bennert, T.; Hanson, D.; Maher, A.; Vitillo, N. Influence of pavement surface type on tire-pavement generated noise. J. Test. Eval. 2005, 33, 94-100.

7. Cho, D.; Mun, S. Study to analyze the effect of vehicles and pavement surface types on noise. J. Appl. Acoust. 2008, 69, 833-843. [CrossRef]

8. Donavan, P.; Lodico, D. Measuring Tire-Pavement Noise at the Source; National Cooperative Highway Research Program, NCHRP Project: 1-44, Report No. 630; Transportation Research Board: Washington, DC, USA, 2009.

9. Edwin, H. Evaluating Tire-Pavement Noise Utilizing the on-Board Sound Intensity Method. Master's Thesis, The State University of New Jersey, New Brunswick, NJ, USA, 2013.

10. Leung, Y.; Tighe, S.; MacDonald, G.; Penton, S. Development of tools to evaluate quiet pavements in the laboratory and field. In Proceedings of the Annual Conference \& Exhibition of the Transportation Association of Canada, Charlottetown, PE, Canada, 17-20 September 2006.

11. Mogrovejo, D.; Flintsch, G.; León, E.; McGhee, I. Effect of air temperature and vehicle speed on tire-pavement noise measured with on-board sound intensity methodology. In Proceedings of the Transportation Research Board 92nd Annual Meeting, Washington, DC, USA, 13-17 January 2013; National Research Council: Washington, DC, USA, 2013.

12. Rochat, J.; Read, D.; Fleming, G. Caltrans Thin Lift Study: Effects of Asphalt Pavements on Wayside Noise; Caltrans Report No. CA 10-0146; California Department of Transportation: Sacramento, CA, USA, 2010.

13. Wang, G.; Shores, R.; Botts, J.; Hibbett, H. On-Board Sound Intensity Tire-Pavement Noise Study in North Carolina; Report No. FHWA/NC/2010-1; North Carolina Department of Transportation: Raleigh, NC, USA, 2011. 
14. National Center for Asphalt Technology (NCAT). Tire-Pavement Noise Study for the Michigan Department of Transportation; Michigan Department of Transportation: Lansing, MI, USA, 2003.

15. Wang, G.; Smith, G.; Shores, R. Pavement noise investigation on North Carolina highways: An on-board sound intensity approach. Can. J. Civ. Eng. 2012, 39, 878-886. [CrossRef]

16. Lédée, A.; Pichaud, F. Temperature effect on tire-road noise. J. Appl. Acoust. 2007, 68, 1-16. [CrossRef]

17. Rochat, J. Investigation of Temperature Correction for Tire-Pavement Noise Measurements; FHWA Report No. FHWA-HEP-11-005; John A. Volpe National Transportation Systems Center: Cambridge, MA, USA; U.S. Department of Transportation: Washington, DC, USA, 2010.

18. ADOT QPPP. Progress Report No. 2 Quiet Pavement Pilot Program. Available online: http://www.rubberpavements.org/Library_Information/SpecificationsHandbook/Section_07_ADOT_ Quiet_Pavement_Pilot_Program/7A_ADOT_Quiet_Pavement_Progress_Report_No_2.pdf (accessed on 18 July 2016).

19. Volpe. FHWA TNM Pavement Effect Implementation Study; U.S. DOT/RITA: Cambridge, MA, USA, 2008.

20. Bendtsen, H.; Lu, Q.; Kohler, E. Temperature Influence on Road Traffic Noise-Californian OBSI Measurement Study; Report 169; Road Directorate, Danish Road Institute: Copenhagen, Denmark, 2009.

21. Sandberg, U. Semi-generic temperature corrections for tire-road noise. In Proceedings of the Inter-Noise, Prague, Czech Republic, 22-25 August 2004.

22. ASTM F2493-08. Standard Specification for P225/65R16 97S Radial Standard Reference Test Tire; American Society for Testing and Materials: Philadelphia, PA, USA, 2008.

23. Bendtsen, H.; Lu, Q.; Kohler, E. Acoustic Aging of Asphalt Pavements: A Californian/Danish Comparison; Report No. UCPRC-RP-2010-0; California Department of Transportation: Berkeley, CA, USA, 2010.

24. Bühlmann, E.; Ziegler, T. Temperature effects on tire/road noise measurements and the main reasons for their variation. In Proceedings of the Inter-Noise, Innsbruck, Austria, 15-18 September 2013.

25. Dare, T.; McDaniel, R.; Shah, A.; Bernhard, R. Hot Mix Asphalt Surface Characteristics Related to Ride, Texture, Friction, Noise and Durability; Report No. MN/RC 2014-07; Minnesota Department of Transportation: Saint Paul, MN, USA, 2014.

26. Irali, F.; Gonzalez, M.; Tighe, S.; Simone, A. Temperature and ageing effects on tire-pavement noise generation in Ontarian road pavements. In Proceedings of the Transportation Research Board 94th Annual Meeting, Washington, DC, USA, 11-15 January 2015.

27. Bendtsen, H.; Andersen, B. Thin Noise Reducing Pavements-Experiences; Report No. 145; Road Directorate, Danish Road Institute: Copenhagen, Denmark, 2005.

28. Bendtsen, H.; Andersen, B. Noise-reducing pavements for highways and urban roads-state of the art in Denmark. In Proceedings of the Association of Asphalt Paving Technologists Technical Sessions, Long Beach, CA, USA, 7-9 March 2005.

29. European Asphalt Pavement Association (EAPA). Abatement of Traffic Noise-The Arguments for Asphalt; EAPA: Brussels, Belgium, 2007.

30. Kohler, E. Findings from the tire-pavement noise study at the UC Pavement research center, part of Caltrans quiet pavement research (QPR) program. In Proceedings of the TRB Summer Meeting, San Luis Obispo, CA, USA, 13-14 June 2007.

31. Kephalopoulos, S.; Paviotti, M.; Lédée, F. Common Noise Assessment Methods in Europe (CNOSSOS-EU); Report EUR 25379 EN; Publications Office of the European Union: Ispra, Italy, 2012.

32. Trevino, M.; Dossey, T. Noise Measurements of Highway Pavements in Texas; Research Report No. FHWA/TX-10/0-5185-3; Center for Transportation Research, The University of Texas at Austin: Austin, TX, USA, 2009.

33. Nicholls, J. Review of UK Porous Asphalt Trials; Report TRL264; Transport Research Laboratory: Crowthorn, UK, 1997.

34. Scofield, L.; Donavan, P. Development of Arizona's Quiet Pavement Research Program; Arizona Department of Transportation: Phoenix, AZ, USA, 2004.

35. Donavan, P. Quiet Pavement Pilot Program: Progress Report 3; Report No. FHWA AZ-12-577; Arizona Department of Transportation: Phoenix, AZ, USA, 2012.

36. Tehrani, F. Noise abatement of hot mix asphalt: A brief review. Int. J. Pavement Res. Technol. 2014, 8, 58-61. 
37. Illingworth \& Rodkin, Inc. I-80 Davies OGAC Pavement Noise Study-A 12 Year Summary Report, 2012. Available online: http://www.dot.ca.gov/hq/env/noise/pub/Davis_12Yr_QPR_Study_May11.pdf (accessed on 20 May 2016).

38. Hanson, D.; Waller, B. 2005 Colorado DOT Tire-Pavement Noise Study; Report No. CDOT-2006-18; Colorado Department of Transportation: Denver, CO, USA, 2006.

39. Hanson, D.; James, R.; NeSmith, C. Tire-Pavement Noise Study; National Center for Asphalt Technology: Auburn, AL, USA, 2004.

40. Sandberg, U. Road traffic noise-the influence of the road surface and its characterization. J. Appl. Acoust. 1987, 21, 97-118. [CrossRef]

41. Rasmussen, R.; Sohaney, C. Tire-Pavement and Environmental Traffic Noise Research Study; The Transtec Group, Inc.: Austin, TX, USA, 2012.

42. Wayson, R.; MacDonald, M.; Martin, A. On-Board Sound Intensity (OBSI) Study-Phase II; John A. Volpe National Transportation Systems Center: Cambridge, MA, USA; Florida Department of Transportation: Tallahassee, FL, USA, 2014.

43. Kowalski, K. Influence of Mixture Composition on the Noise and Frictional Characteristics of Flexible Pavements. Ph.D. Thesis, Purdue University, West Lafayette, IN, USA, 2007.

44. Laboratoire Régional des Ponts et Chaussée (LRFC). The SPB Database of the Strasbourg LRPC in France; Regional Laboratory for Roads and Bridges: Strasbourg, France, 2005.

45. Donavan, P. Comparative Measurements of Tire-Pavement Noise in Europe and the United States; Report Number: FHWA/CA/MI-2006/09; California Department of Transportation: Sacramento, CA, USA, 2006.

46. Timm, D.; West, R.; Priest, A.; Powell, B.; Selvaraj, I.; Zhang, J.; Brown, R. Phase II NCAT Test Track Results; NCAT Report No. 06-05; National Center for Asphalt, Technology: Auburn, AL, USA, 2006.

47. Sousa, J.; Way, G.; Zhu, H. Asphalt-Rubber Noise Data Compilation (Synthesis of Current Practices). Available online: http://www.asphaltrubber.org/Noise_Report_Synthesis/Noise_Report_October_2004 (accessed on 14 April 2015).

48. Meiarashi, S.; Ishida, M.; Fujiwara, T.; Hasebe, M.; Nakatsuji, T. Noise reduction characteristics of porous elastic road surfaces. J. Appl. Acoust. 1996, 47, 239-250. [CrossRef]

49. Bernhard, R.; Wayson, R. An Introduction to Tire-Pavement Noise; Final Research Report SQDH 2005-1; Purdue University: West Lafayette, IN, USA, 2005.

50. McDaniel, R. Design of fine-graded superpave mixes. In Proceedings of the A Tire-Pavement Noise Symposium, Lafayette, IN, USA, 1-3 November 2005.

51. Ongel, A.; Kohler, E.; Nelson, J. Acoustical Absorption of Open-Graded, Gap-Graded, and Dense-Graded Asphalt Pavements; Research Report No. UCPRC-RR-2007-12; California Department of Transportation: Sacramento, CA, USA, 2007.

52. Descornet, G. Low-noise road surfaces: European state of the art. J. Assoc. Asph. Paving Technol. 2005, 74, 1059-1083.

53. Huschek, S. Influence of road surface roughness on tire noise generation in the Federal Republic of Germany. In Surface Characteristics of Roadways: International Research and Technologies; Meyer, W.E., Reichert, J., Eds.; ASTM STP 1031; American Society for Testing and Materials: Philadelphia, PA, USA, 1990; pp. 430-441.

54. Faure, B.; Hamet, J.F.; Kestemont, X.; Luminari, M.; Quaresma, L.; Sandulli, D. Traffic Noise and Road Surfaces: State of the Art; Belgian Road Research Centre: Brussels, Belgium, 2000.

55. Izevbekhai, B. Tire-Pavement Interaction Noise of Concrete Pavements. Ph.D. Thesis, University of Minnesota, Minneapolis, MN, USA, 2012.

56. Rasmussen, R.; Garber, S.; Fick, G.; Ferragut, T.; Wiegand, P. How to Reduce Tire-Pavement Noise: Interim Better Practices for Constructing and Texturing Concrete Pavement Surface; Research Report Pooled Fund TPF-5(139); National Concrete Pavement Technology Center: Ames, IA, USA, 2008.

57. Rochat, J.; Hastings, A.; Read, D.; Lau, M. FHWA Traffic Noise Model (TNM) Pavement Effects Implementation Study: Progress Report 1; Research Report No. DOTVNTSC-FHWA-12-01; U.S. Department of Transportation; Federal Highway Administration: Washington, DC, USA, 2012.

58. Samuels, S.; Hall, A. The acoustics attributes of Queensland pavement surfaces-the QDMR pavement surface noise resources manual. In Proceedings of the Australian Acoustical Society Annual Conference, Busselton, Australia, 9-11 November 2005; pp. 259-263. 
59. Sandberg, U.; Ejsmont, J. Texturing of cement concrete pavements to reduce traffic noise. J. Noise Control Eng. 1998, 46, 231-243. [CrossRef]

60. Smit, F. Synthesis of NCAT Low-Noise HMA Studies; NCAT Report 08-01; National Center for Asphalt Technology: Auburn, AL, USA, 2008.

61. Swift, J.; Bris, P.; Horoshenkov, K. Acoustic absorption in re-cycled rubber granulate. J. Appl. Acoust. 1999, 57, 203-212. [CrossRef]

62. Shatanawi, K. The Effects of Crumb Rubber Particles on Highway Noise Reduction-A Laboratory Study. Ph.D. Thesis, Clemson University, Clemson, SC, USA, 2008.

63. Biligiri, K. Effect of pavement materials' damping properties on tire-road noise characteristics. J. Constr. Build. Mater. 2013, 49, 223-232. [CrossRef]

64. Liao, G.; Sakhaeifer, M.; Heitzman, M.; West, R.; Waller, B.; Wang, S.; Ding, Y. The effects of pavement surface characteristics on tire-pavement noise. J. Appl. Acoust. 2014, 76, 14-23. [CrossRef]

65. Paje, S.; Bueno, M.; Teran, F.; Miro, R.; Perez-Jiminez, F. Acoustic field evaluation of asphalt mixtures with crumb rubber. J. Appl. Acoust. 2010, 71, 578-582. [CrossRef]

66. Paje, S.; Luong, J.; Vázquez, V.; Bueno, M.; Miró, R. Road pavement rehabilitation using a binder with a high content of crumb rubber: Influence on noise reduction. J. Constr. Build. Mater. 2013, 47, 789-798. [CrossRef]

67. Parnell, J.; Samuel, S. A comparison of tire-pavement noise generated on NSW pavements to international studies. In Proceedings of the Acoustics, Christchurch, New Zeland, 22-26 November 2006.

68. Harvey, J.; Kohler, E. Quieter Pavement Research: Concrete Pavement Tire Noise; Report No. CA12-1200; California Department of Transportation: Sacramento, CA, USA, 2011.

69. Dare, T.; Bernhard, R. Predicting tire-pavement noise on longitudinally ground pavements using a nonlinear model. In Proceeding of the Inter-Noise, Ottawa, ON, Canada, 23-26 August 2009; p. 4047.

70. Cesbron, J.; Ledee, F.; Duhamel, D.; Yin, H.; Houedec, D. Experimental study of tire-road contact forces in rolling conditions for noise prediction. J. Sound Vib. 2009, 320, 125-144. [CrossRef]

71. Rasmussen, R.; Mun, E.; Farragut, T.; Wiegand, P. A comprehensive field study on concrete pavement solutions for reducing tire-pavement noise. In Proceedings of the Inter-Noise, Honolulu, HI, USA, 3-6 December 2006; p. 3900.

72. Rasmussen, R.; Mun, E.; Karamihas, S.; Chang, G. Relating pavement texture to tire-pavement noise. In Proceedings of the Inter-Noise, Honolulu, HI, USA, 3-6 December 2006; p. 3910.

73. Abo-Quadis, S.; Alhiary, A. Effect of traffic characteristics and road geometric parameters on developed traffic noise levels. In Proceedings of the 83rd Transportation Research Board Annual Meeting (CD), Washington, DC, USA, 11-15 January 2004.

74. Gardziejczyk, W.; Berengier, M. Tire-road noise in aspect of road surface construction technology. Arch. Civ. Eng. 2000, 46, 25-38.

75. Canale, S.; Malgarini, M.; Puzelli, G.; Ricci, R. The differences of sound pressure level on Italian highway pavements. In Proceedings of the International Tire-Road Noise Conference, Gothenburg, Sweden, 8-10 August 1990.

76. Huang, S.; Branthaver, J.; Robertson, R.; Kim, S. Effect of film thickness on the rheological properties of asphalts in contact with aggregate surface. J. Transp. Res. Board 1998, 1638, 31-39. [CrossRef]

77. Von Meier, A.; Van Mokland, G.J.; Heerken, J.C. Noise optimized road surfaces and further improvements by tire choice. In Proceedings of the International Tire-Road Noise Conference-1990, Gothenburg, Sweden, 8-10 August 1990.

78. Rochat, J.; Read, D. Effective flow resistivity of highway pavements. J. Acoust. Soc. Am. 2013, $134,4710$. [CrossRef] [PubMed]

79. Marolf, A.; Neithalath, N.; Sell, E.; Weiss, J.; Olek, J. Influence of aggregate size and gradation on the acoustic absorption of enhanced porosity concrete. ACI Mater. J. 2004, 101, 82-91.

80. Crocker, M.; Hanson, D.; Li, Z.; Karjatkar, R.; Vissamraju, K. Measurement of acoustical and mechanical properties of porous road surfaces and tire and road noise. J. Transp. Res. Board 2004, 1891, 16-22. [CrossRef]

81. Kumar, A.; Mondal, P.; Vijay, P.; Bhangale, U.; Tyagi, D. Comparative study of sound absorption coefficients on different types of road surfaces using non-destructive method as per ISO 13472-2:2010. Phys. Rev. Res. Int. 2011, 1, 45-56.

82. Rochat, J.; Donavan, P. Investigations of effect of porous pavement on traffic noise and traffic noise prediction. J. Transp. Res. Board 2013, 2362, 42-48. [CrossRef] 
83. Rochat, J.; Donavan, P.; Seybert, A.; Dare, T. Pavement sound absorption measurements in the USA. In Proceedings of the Inter-Noise, New York, NY, USA, 19-22 August 2011.

84. Sohaney, R.; Rasmussen, R.; Seybert, A.; Donavan, P. New ISO test track specification for measuring tire and vehicle noise. In Proceedings of the INCE 25th Annual Conference, Portland, OR, USA, 25-27 July 2011.

85. Nelson, J.; Kohler, E.; Rymer, B.; Ongel, A. Acoustical absorption of porous pavement. In Proceedings of the 87th Annual Meeting of Transportation Research Board (TRB), Washington, DC, USA, 13-17 January 2008; National Research Council: Washington, DC, USA, 2008.

86. ANSI S1.18. Template Method for Ground Impedance; American National Standards Institute (ANSI) and Acoustical Society of America Standards: New York, NY, USA, 1999.

87. Sachakamol, P.; Dai, L. Parametric influence on the sound absorption coefficient of porous asphalt. In Proceedings of the ASME International Mechanical Engineering Congress and Exposition, Lake Buena Vista, FL, USA, 13-19 June 2009.

88. Raimundo, I.; Freitas, E.; Inácio, O.; Pereira, P. Sound absorption coefficient of wet gap graded asphalt mixtures. In Proceedings of the Inter-Noise, Lisbon, Portugal, 13-16 June 2010.

89. Descornet, G. A criterion for optimizing surface characteristics. J. Transp. Res. Board 1989, 1215, $173-177$.

90. Ahammed, A.; Tighe, S. Pavement surface mixture, texture and skid resistance: A factorial analysis. In Proceedings of the Airfield and Highway Pavements Conference, Seattle, WA, USA, 15-18 October 2008; pp. 370-384.

91. Franklin, R.; Harland, D.; Nelson, P. Road Surfaces and Traffic Noise; TRRL Report No. 89; Publication of the Transport and Road Research Laboratory (TRRL), Department of Transport: Berkshire, UK, 1979.

92. Jaeckel, J.; Kuemmel, D.; Becker, Z.; Satanovsky, A.; Sonntag, R. Noise Issues of Concrete-Pavement Texturing. J. Transp. Res. Board 2000, 1702, 69-79. [CrossRef]

93. Wielen, F. Vehicle noise on experimental concrete surfaces. In Proceedings of the Annual Transportation Convention-1989, Pretoria, South Africa, 1989; p. 1.

94. Schlaefer, J.; LaForce, R. Noise and Skid Measurements on US 285 in the Turkey Creek Canyon Area; Report No. CDOT-R1-R-2001-9; Colorado Department of Transportation: Aurora, CO, USA, 2001.

95. Kuemmel, D.; Sonntag, R.; Crovetti, J.; Becker, Y.; Jaeckel, J.; Satanovsky, A. Noise and Texture on PCC Pavements-Results of a Multi-State Study; Report No. WI/SPR-08-99; Wisconsin Department of Transportation: Madison, WI, USA, 2000.

96. Ahammed, M. Safe, Quiet and Durable Pavement Surfaces. Ph.D. Thesis, University of Waterloo, Waterloo, ON, Canada, 2009.

97. Ahammed, M.; Tighe, S. Quiet Pavements: Fact or Fiction?; Materials Engineering and Research Office Report; 2007 Highway Infrastructure Innovation Funding Program Research Project No. 999; Ministry of Transportation Ontario: Toronto, ON, Canada, 2008.

98. McDaniel, R.; Thornton, W. Field evaluation of a porous friction course for noise control. In Proceedings of the 84th Annual Meeting of Transportation Research Board (TRB), Washington, DC, USA, 9-13 January 2005; National Research Council: Washington, DC, USA, 2005.

99. Kugler, B.; Commins, D.; Galloway, W. Highway Noise; a Design Guide for Prediction and Control; National Cooperative Highway Research Program, Report 174; Transportation Research Board, National Research Council: Washington, DC, USA, 1974.

100. Wayson, R.; Chovarelli, M.; MacDonald, M. Testing the AAMA community noise model. In Proceedings of the 78th Transportation Research Board Annual Meeting (CD), Washington, DC, USA, 10-14 January 1999.

101. TemaNord. Road Traffic Noise-Nordic Prediction Method; Report 1996:525; Nordic Council of Ministers: Copenhagen, Denmark, 1996.

102. Jonasson, H.; Storeheier, S. Nord 2000: New Nordic Prediction Method for Road Traffic Noise; SP Report 2001-10; Swedish National Testing and Research Institute (SP): Boras, Sweden, 2001.

103. Descornet, G.; Sandberg, U. Road surface influence on tire/road noise-part II. In Proceedings of the Inter-Noise, Miami, FL, USA, 8-10 December 1980.

104. Sandberg, U.; Descornet, G. Road surface influence on tire-road noise-Part I. In Proceedings of the Inter-Noise Conference, Miami, FL, USA, 8-10 December 1980.

105. Rasmussen, R. Measuring and modeling tire-pavement noise on various concrete pavement textures. J. Noise Control Eng. 2009, 57, 139-147. [CrossRef] 
106. Fujikawa, T.; Oshino, Y.; Mikami, T.; Tachibana, H. Examination of road roughness parameters for abating tire vibration and radiated noise. J. Noise Control Eng. 2009, 57, 77-83. [CrossRef]

107. Reyes, C.; Harvey, J. A method for prediction sound intensity noise levels using laboratory pavement cores. In Proceedings of the Noise-Con, Portland, OR, USA, 25-27 July 2011.

108. Brinkmeier, M.; Nackenhorst, U.; Estorff, O.; Petersen, S. Physically based modelling of tire-rolling-noise by a finite element approach. In Proceedings of the Inter-Noise, Prague, Czech Republic, 22-25 August 2004.

109. Brinkmeier, M.; Nackenhorst, U.; Biermann, J.; Estorff, O. Prediction of tire/road noise-modelling and validation. In Proceedings of the Inter-Noise, Istanbul, Turkey, 28-31 August 2007.

110. Doelman, N.; Mulder, H.; Eerden, F.; Roo, F. 3-D characterization of road surface textures in TRIAS. In Proceedings of the Inter-Noise, Prague, Czech Republic, 22-25 August 2004.

111. Eerden, F.; Gerretsen, E.; Roo, F.; Mulder, E.; Schoen, E. A parameter study with the tire-road noise simulation tool TRIAS. In Proceedings of the Inter-Noise, Dearborn, MI, USA, 19-21 August 2002.

112. Roo, F.; Gerretsen, E.; Hoffmans, W.; Doelman, N. Dutch tire road noise emission model-adjustments and validation. In Proceedings of the Inter-Noise, Fort Lauderdale, FL, USA, 2-4 December 1999.

113. Roo, F.; Gerretsen, E. TRIAS-Tire road interaction acoustic simulation model. In Proceedings of the Inter-Noise, Nice, France, 27-30 August 2000.

114. Roo, F.; Gerretsen, E.; Mulder, E. Predictive performance of the tire road noise model TRIAS. In Proceedings of the Inter-Noise, The Hague, The Netherland, 27-30 August 2001.

115. Anderson, G.; Lee, C.; Fleming, G.; Menge, C. FHWA Traffic Noise Model, Version 1.0: User's Guide; Report No. FHWA-PD-96-009 and DOT VNTSC-FHWA-98-1; John, A., Ed.; Volpe National Transportation Systems Center: Cambridge, MA, USA, 1998.

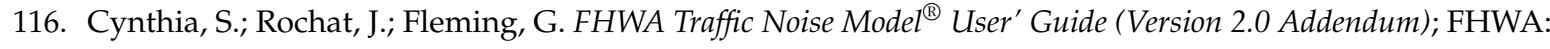
Washington, DC, USA, 2002.

117. Menge, C.; Rossano, F.; Anderson, G.; Bajdek, C. FHWA Traffic Noise Model, version 1.0: Technical Manual; Report No. FHWA-PD-96-010 and DOT-VNTSC FHWA-98-02; U.S. Department of Transportation: Washington, DC, USA; John A. Volpe National Transportation Systems Center: Cambridge, MA, USA, 1998.

118. Burge, P.; Travis, K.; Rado, Z. Transverse-tined and longitudinal diamond-ground texturing for newly constructed concrete pavement: A comparison. J. Transp. Res. Board 2002, 1792. [CrossRef]

119. Rochat, J.; Fleming, G. Addendum to Validation of FHWA's Traffic Noise Model ${ }^{\circledR}$ (TNM): Phase 1; Report No. FHWA-EP-02-031 Addendum and DOT-VNTSC-FHWA-02-01 Addendum; U.S. Department of Transportation: Washington, DC, USA; Volpe National Transportation Systems Center: Cambridge, MA, USA, 2004.

120. Donavan, P.; Lodico, D. Measuring Tire-Pavement Noise at the Source: Precision and Bias Statement; National Cooperative Highway Research Program, NCHRP Project: 1-44; Transportation Research Board: Washington, DC, USA, 2011.

(C) 2016 by the author; licensee MDPI, Basel, Switzerland. This article is an open access article distributed under the terms and conditions of the Creative Commons Attribution (CC-BY) license (http:/ / creativecommons.org/licenses/by/4.0/). 